\title{
PRODUÇÃO DE FORRAGEM EM PASTAGEM NATURAL COM O USO DE ESTERCO LÍQUIDO DE SUÍNOS ${ }^{(1)}$
}

\author{
R. DURIGON(2), C. A. CERETTA(3), C. J . BASSO(4), \\ L. A. R. BARCELLOS ${ }^{(5)} \&$ P. S. PAVINATO(6)
}

\begin{abstract}
RESUMO
A produção de matéria seca por pastagem natural normalmente é baixa em virtude da limitação de nutrientes di sponíveis no solo, a qual pode ser corrigida com o uso de esterco líquido de suínos. Visando avaliar a eficiência e a freqüência de utilização de ester co líquido de suínos na produção de matéria seca e acúmulo de nutrientes em pastagem natural, foi realizado um experimento de novembro de 1995 a novembro de 1999, no município de Paraíso do Sul (RS), em condomínio de suinocultores. Os tratamentos consistiram na aplicação de doses de 0, 20 e $40 \mathrm{~m}^{3} \mathrm{ha}^{-1}$ de esterco líquido de suínos, aplicadas em intervalos de 45 a 60 dias. Antes das aplicações do esterco, foram feitas coletas para determinação da produção de matéria seca da pastagem natural. Posteriormente, toda a área foi roçada, a forragem retirada e o esterco aplicado. A aplicação de $20 \mathrm{~m}^{3} \mathrm{ha}^{-1} \mathrm{em}$ intervalos de 45 a 60 dias mostrou-se mais eficiente para o suprimento de nutrientes às plantas da pastagem natural, enquanto a quantidade de fósforo absorvido pelas plantas na pastagem natural foi muito baixa em relação à quantidade aplicada por meio do esterco. Deve-se dar especial atenção às quantidades de potássio e magnésio presentes no esterco líquido de suínos, considerando suas altas taxas de exportação pela matéria seca. Devem-se diminuir as quantidades de esterco aplicadas nas estações de outono e inverno, em decorrência das restrições climáticas, especialmente temperaturas baixas, e da produção de matéria seca pela pastagem natural.
\end{abstract}

Termos de indexação: chorume de suínos, dejetos de animais, esterco.

\footnotetext{
(1) Parte da Tese de Mestrado em Agronomia do primeiro autor. Programa de Pós-Graduação em Agronomia, Universidade Federal de Santa Maria - UFSM. Trabalho parcialmente financiado pela FAPERGS e PRONEX. Recebido para publicação em janeiro de 2001 e aprovado em julho de 2002.

(2) Engenheiro-Agrônomo, Mestre em Biodinâmica do Solo, Universidade Federal de Santa Maria - UFSM. Departamento de Solos, CEP 97105-900 Santa Maria (RS). E-mail: rdurigon@bol.com.br

(3) Professor Titular do Departamento de Solos, UFSM. Bolsista do CNPq. E-mail: ceretta@ccr.ufsm.br

(4) Doutorando em Biodinâmica do Solo, UFSM

(5) Engenheiro-Agrônomo, M.S. em Biodinâmica do Solo, UFSM.

(6) Graduando em Agronomia, UFSM. Bolsista do BIC-CNPq. E-mail: pspavinato@bol.com.br
} 


\title{
SUMMARY: FORAGE DRY MATTER PRODUCTION OF NATIVE PASTURE UNDER APPLICATION OF LIQUID SWINE MANURE
}

\begin{abstract}
Forage dry matter production of native pastures in southern Brazil is usually low due to therestricted soil nutrient availability - a limitation that can becompensated by application of liquid swine manure. In an experiment carried out from November 1995 to November 1999, in an area near a swinefarm in Paraíso do Sul County, Ri o Grandedo Sul State, the efficiency and frequency of liquid swine manure application in relation to dry matter production and nutrient uptakeby nativegrass pasturewereevaluated. Liquid swinemanure $\left(0,20\right.$ and $\left.40 \mathrm{~m}^{3} \mathrm{ha}^{-1}\right)$ was applied every 45 to 60 days. Before each manure application, the pasturedry matter was measured and the plots mowed. A dose of $20 \mathrm{~m}^{3} \mathrm{ha}^{-1}$, applied at intervals of 45 to 60 days, was most efficient to supply nutrients for thenativegrass pasture. Phosphorus amounts introduced by theliquid swinemanure were much greater than what was taken up by the pasture. Potassium and $\mathrm{Mg}$ contents in the liquid swine manure should be carefully considered, due to their high extraction rates by the native pasture During the low temperature periods of fall and winter, when the dry matter production of thenative pasture is restricted, a reduction in manureapplication rates becomes necessary.
\end{abstract}

Index terms: pig slurry, animal residues, manure.

\section{INTRODUÇÃO}

A aplicação de esterco de suínos não deve ser vista como uma mera aplicação de nutrientes ao solo. A utilização de esterco de suínos em solos agrícolas requer uma combinação harmoniosa dos princípios da ciência do solo, saúde pública, hidrologia e economia.

A baixa concentração de nutrientes limita o aproveitamento do esterco líquido de suínos, pois aumenta os custos de armazenamento, transportee aplicação por unidade de nutriente, restringindo sua utilização como fertilizante em áreas próximas à sua geração earmazenamento. Por isso, Schmitt (1995), ao analisar 54 propriedades com exploração desuínos em Videira (SC), concluiu que apenas $60 \%$ das propriedades fazem uma distribuiçãoeconomicamente viável de esterco líquido de suínos.

A quantidade de esterco, economicamente viável, dependerá não só da composição do esterco, do teor de matéria orgânica, da classetextural e do nível de fertilidade do solo, mas também da exigência nutricional relativa da cultura explorada e das condições de clima do local. Segundo Chambers et al. (2000), para diminuir a lixiviação de nitrato, não se recomendam aplicações de esterco com el evado teor de $\mathrm{N}$ disponível no período de outono e inverno, dadas as limitações detemper atura para o crescimento das plantas. Respeitando essas pré-condições, para a região do oeste catarinense, a aplicação de esterco em doses variando em torno de $40 \mathrm{~m}^{3} \mathrm{ha}^{-1}$ aumentou as produções de milho e feijão, além de mostrar redução substancial no gasto com fertilizantes (Scherer et al., 1986; Konzen et al., 1989).
No esterco líquido de suínos, grande parte do nitrogênio está presente na forma mineral e por isso prontamente disponível às plantas e sujeito a ser perdido por volatilização ou lixiviação. Aita (1987), em amostras de esterco suíno col etadas em esterqueiras da região oeste do estado de Santa Catarina, observou que cerca de 56 \% do nitrogênio do esterco estava na forma amoniacal, enquanto Vetter \& Kowalewsky (1986) encontraram percentuais de 30 a $91 \%$. Essa é uma das justificativas pelas quais Sullivan et al. (2000) determinaram uma reconversão aparente acumulada de $\mathrm{N}$ variando de 24 a $38 \%$, quando aplicaram esterco líquido de bovinos em pastagem perene. A plicações do esterco em fevereiro e após o verão em solo bem drenado proporcionaram maior produção de forragem na primavera em relação a aplicações de meia-estação.

O esterco líquido de suínos pode acarretar aumento da disponibilidade de nutrientes em áreas com pastagem natural no Rio Grande do Sul, pois existem aproximadamente 10 milhões de hectares cobertos com pastagem natural e explorados com pecuária extensiva, basicamente criação de bovinos e ovinos (IBGE, 1995), e os solos apresentam, de maneira geral, textura média a arenosa, reação ácida, baixo teor de matéria orgânica e baixa disponibilidade de nutrientes.

SegundoJ acques et al. (1995), no Rio Grande do Sul, existem uma estação quente (setembroa abril) e uma estação fria (maio a agosto) de crescimento da pastagem natural, sendo a primeira relativamente mais longa que a segunda. Nestas condi ções, os teores de nutrientes nas pastagens não 
atingiram o valor mínimo para atender às necessidades dos bovinos, sendo 98,2 \% deficientes em P, 16,4 \% em K e 14,5 \% em Mg (Senger et al., 1996). Os mesmos autores relataram também deficiência de $P$ em todas as estações do ano e aumento da deficiência de Mg no período de inverno.

Nestas condições, a aplicação de esterco líquido de suínos representaria um aporte de fósforo contínuo no solo, porque aproximadamente dois terços estão numa forma não-solúvel em água e combinados com compostos orgânicos de natureza variada. O potássio éum el emento que se encontra no esterco totalmente na forma solúvel e se torna disponível às plantas logo após a sua aplicação, com efeito residual muito curto.

O trabalho baseia-se na hipótese de que, com aplicações freqüentes de esterco líquido de suínos, as doses mais el evadas tornam-se menos eficientes à produção de matéria seca de pastagem natural, principal mente nas estações de outono einverno. $O$ trabalho tem como objetivos: avaliar a eficiência de aplicações de doses de esterco líquido de suínos na produção de matéria seca em pastagem natural; determinar os percentuais de acréscimo de nutrientes acumulados nos tecidos vegetais proporcionados pela aplicação de esterco líquido de suínos e avaliar a utilização de doses de esterco líquido de suínos em pastagem natural de acordo com as estações do ano.

\section{MATERIAL E MÉTODOS}

O experimento foi realizado de novembro de 1995 a novembro de 1999. A área experimental pertence a um condomínio suinícola situado no município de Paraíso do Sul, na região da Depressão Central do Rio Grande do Sul. Utilizou-se o Alissolo Crômico órtico típico (EMBRAPA, 1999), pertencente à unidade demapeamentoSanta Maria, medianamente profundo, com cor bruno-acinzentada, no horizonte $A$, e bruno-amarelada, no horizonte $B$, textura média, friável e imperfeitamente drenado. A unidade de mapeamento Santa Maria abrange as regiões da Depressão Central eparte da Campanha do Rio Grande do Sul, cobrindo uma área de $5.050 \mathrm{~km}^{2}$, o que representa $1,87 \%$ da área total do Estado (Brasil, 1973).

Os resultados das análises químicas do solo estratificado na camada de $0-10$ e $10-20 \mathrm{~cm}$ de profundidade encontram-se no quadro 1 . A vegetação natural existente na área, quando da instalação do experimento, era composta predominantemente por grama forquilha (Paspalum notatum) e desmodium (Desmodium sp.).

As doses de 0, 20 e $40 \mathrm{~m}^{3}$ ha-1 de esterco líquido de suínos foram aplicadas em intervalos de 45 a 60 dias, o que corresponderia ao intervalo de tempo no qual os tanques de armazenamento (esterqueiras) estariam chei os novamente e o produtor deveria dar um destino ao esterco. O delineamento experimental utilizado foi de blocos casualizados com quatro repetições. As uni dades experimentais constituíramse de parcelas de 4,0 × 3,5 m.

O esterco líquido de suínos foi aplicado manual mente logo após cada col eta de amostras da matéria vegetal aérea e corte e retirada total da vegetação da área experimental. No momento de cada aplicação do esterco, era feita uma coleta do esterco para determinação da matéria seca e nutrientes, segundo o método descrito por Barcellos (1992). Anál ise detal hada do esterco foi real izada com base no método proposto por Tedesco et al. (1995).

Durante os quatro anos do experimento, foram real izadas 28 aplicações de ester colíquido de suínos, cuja concentração média de nutrientes e a quantidade total aplicada em cada dose encontramse no quadro 2.

A produção de matéria seca da pastagem natural foi obtida pela coleta da parte aérea das plantas, amostrando-se uma área de 0,75 $\mathrm{m}^{2}$ por parcela, a partir detrês subamostras de 0,5 x 0,5 m. As col etas foram feitas em intervalos de 45 a 60 dias após a instal ação do experimento, eas amostras foram secas em estufa $\left(65^{\circ} \mathrm{C}\right)$ até peso constante. A pós a secagem definitiva, as amostras foram moídas em moinho Willey (<40 mesh) para análise de N, P, K, Ca e Mg, segundo Tedesco et al. (1995). As estações de verão,

Quadro 1. Características do solo sob pastagem natural em duas profundidades

\begin{tabular}{|c|c|c|c|c|c|c|c|c|c|c|c|c|c|c|}
\hline \multirow[b]{2}{*}{ Profundidade } & \multirow[b]{2}{*}{ Argila } & \multirow{2}{*}{$\underset{(1: 1)}{\mathbf{p H}-\mathrm{H}_{2} \mathrm{O}}$} & \multirow{2}{*}{$\begin{array}{l}\text { Índice } \\
\text { SMP }\end{array}$} & \multirow[b]{2}{*}{$\mathbf{P}$} & \multirow[b]{2}{*}{$\mathbf{K}$} & \multirow[b]{2}{*}{ M.o. } & \multirow[b]{2}{*}{ Al } & \multirow[b]{2}{*}{$\mathrm{Ca}$} & \multirow[b]{2}{*}{$\mathbf{M g}$} & \multirow[b]{2}{*}{$\mathbf{H}+\mathbf{A} \mathbf{I}$} & \multicolumn{2}{|c|}{ СТC } & \multicolumn{2}{|c|}{ Saturação } \\
\hline & & & & & & & & & & & E fetiva & pH 7,0 & Al & B ases \\
\hline $\mathrm{cm}$ & $\mathrm{g} \mathrm{kg}^{-1}$ & & & $-m g c$ & $m^{-3}-$ & $\mathrm{g} \mathrm{kg}^{-1}$ & 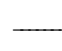 & $\ldots$ & $-\mathrm{Cr}$ & $\mathrm{hol}_{\mathrm{c}} \mathrm{dm}^{-3}$ & 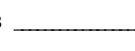 & - & 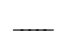 & $\%$ \\
\hline $0-10$ & 150 & 5,2 & 4,6 & 12,3 & 190 & 35 & 4,1 & 3,8 & 1,5 & 12,2 & 9,9 & 17,7 & 41 & 33 \\
\hline $10-20$ & 160 & 5,1 & 4,7 & 14,0 & 192 & 28 & 4,0 & 3,8 & 1,4 & 11,5 & 9,7 & 17,0 & 41 & 33 \\
\hline
\end{tabular}

Conforme tabelas para interpretação dos resultados analíticos para o RS e SC constantes em Comissão (1995), os teores de fósforo são considerados médio, potássio trocável alto, cálcio médio e magnésio alto. 
Quadro 2. Concentração média e quantidade total de nutrientes e carbono aplicadas em pastagem natural na forma de esterco líquido de suínos durante 48 meses

\begin{tabular}{|c|c|c|c|c|c|c|}
\hline Dose de esterco & $\mathbf{N}$ & $\mathbf{P}$ & K & $\mathrm{Ca}$ & Mg & C \\
\hline \multirow[t]{3}{*}{$\mathrm{m}^{3} \mathrm{ha}^{-1}$} & \multicolumn{6}{|c|}{ Concentração média no esterco líquido de suínos(1), $\mathrm{kg} \mathrm{m}^{-3}$} \\
\hline & 3,23 & 3,64 & 2,64 & 1,00 & 0,96 & 15 \\
\hline & \multicolumn{6}{|c|}{ Quantidade aplicada via esterco, $\mathrm{Mg} \mathrm{ha}^{-1}$} \\
\hline 20 & 1,81 & 2,04 & $\begin{array}{l}1,48 \\
295\end{array}$ & 0,56 & 0,54 & $\begin{array}{r}8,4 \\
168\end{array}$ \\
\hline
\end{tabular}

(1) Média das 28 amostras de esterco líquido de suínos usadas durante o experimento, as quais apresentaram um teor médio de $5 \%$ de matéria seca.

outono, inverno e primavera correspondem aos períodos compreendidos entre 21/12 e 20/03, 21/03 e 20/06, 21/06 e20/09, e21/09 e20/12, respectivamente.

No cál culo do incremento na produçãoacumulada de matéria seca da pastagem natural por metro aúbico de esterco aplicado, descontou-sea quantidade de matéria seca produzida onde não foi aplicado esterco. Calculou-se a eficiência nutricional da seguinte maneira: $\mathrm{kg}$ de MS produzida com esterco menos $\mathrm{kg}$ de MS produzida sem esterco dividido pel os $\mathrm{kg}$ de nutriente aplicado na forma do esterco. A eficiência de aquisição de nutrientes correspondeu a: kg de nutriente absorvido com apl icação de esterco menos $\mathrm{kg}$ de nutriente absorvido sem aplicação de esterco dividido pelos $\mathrm{kg}$ de nutriente aplicado na forma do esterco.

A análise estatística dos resultados constou da análise de variância, análise de regressão e teste Duncan a $5 \%$.

\section{RESULTADOS E DISCUSSÃO}

\section{Esterco líquido de suínos aplicado em pastagem natural durante quatro anos}

A aplicação deesterco líquido de suínos promoveu acréscimo na produção de matéria seca da pastagem natural (Figura 1). Aos 8,3 meses, o incremento na produção acumulada de matéria seca foi de 44 e $70 \%$ com o uso das doses de 20 e $40 \mathrm{~m}^{3}$ ha-1 de esterco, respectivamente. Com o passar do tempo, o efeito residual foi assumindo maior contribuição à produção de matéria seca, tendo os percentuais de acréscimo atingido 109 e $155 \%$ com as doses de 20 e $40 \mathrm{~m}^{3} \mathrm{ha}^{-1}$, respectivamente, ao final de 48 meses. O efeitoresidual foi demonstrado por Durigon (2000), que analisou as características químicas do solo neste mesmo trabal ho e observou que os teores de fósforo, cálcio e magnésio foram incrementados ao longo dos quatro anos. Por isso que, em situações onde há disponibilidade de esterco para aplicação de doses maiores, seria conveniente a introdução de plantas forrageiras com mai or potencial de produção de matéria seca.

A definição de doses depende também da eficiência de uso do esterco aplicado. Nesse caso, a dose de $20 \mathrm{~m}^{3}$ ha $^{-1}$ proporcionou o maior incremento acumulado na produção de matéria seca da pastagem natural por $\mathrm{m}^{3}$ de esterco aplicado (Figura 2). Observa-se que o incremento na produção de matéria seca com a dose de $20 \mathrm{~m}^{3}$ ha-1 aumenta com o tempo, tanto que, aos 8,3 meses, a diferença no incremento com as doses de 20 para $40 \mathrm{~m}^{3} \mathrm{ha}^{-1}$ foi de $26 \%$, elevando-se para $40 \%$ aos 48 meses. I sso demonstra que, na dose de $40 \mathrm{~m}^{3} \mathrm{ha}^{-1}$, foi aplicada uma quantidade de esterco acima da capaci dade de utilização pela pastagem natural .

A quantidade de $\mathrm{N}$ acumulado na matéria seca da pastagem até os 48 meses foi de 960 e $1.274 \mathrm{~kg} \mathrm{ha}^{-1}$ nas doses de 20 e $40 \mathrm{~m}^{3} \mathrm{ha}^{-1}$, respectivamente. I sso significa que o aproveitamento do $\mathrm{N}$ aplicado por meio do esterco nas respectivas doses foi de 29 e $23 \%$ (Figura 3). Esses percentuais deaproveitamento

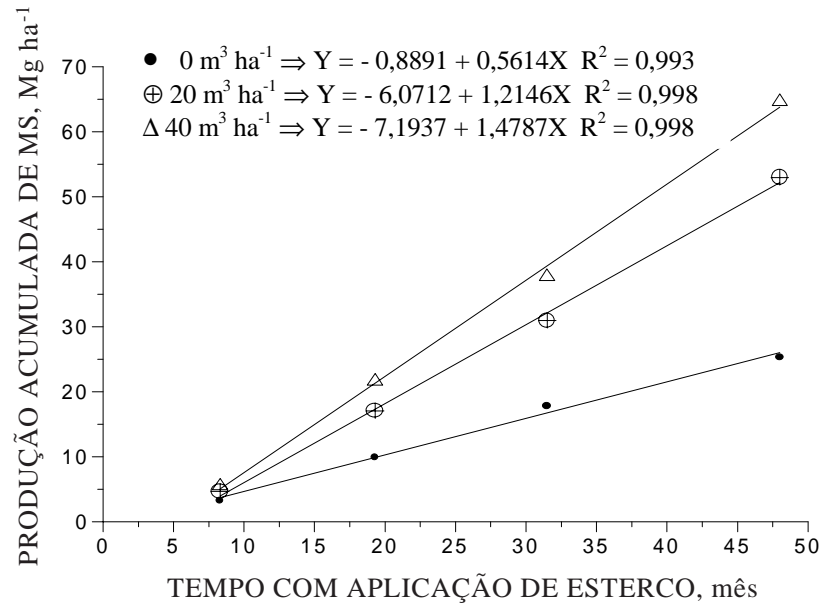

Figura 1. Produção acumulada de matéria seca em pastagem natural com aplicação de doses de esterco líquido de suínos. 


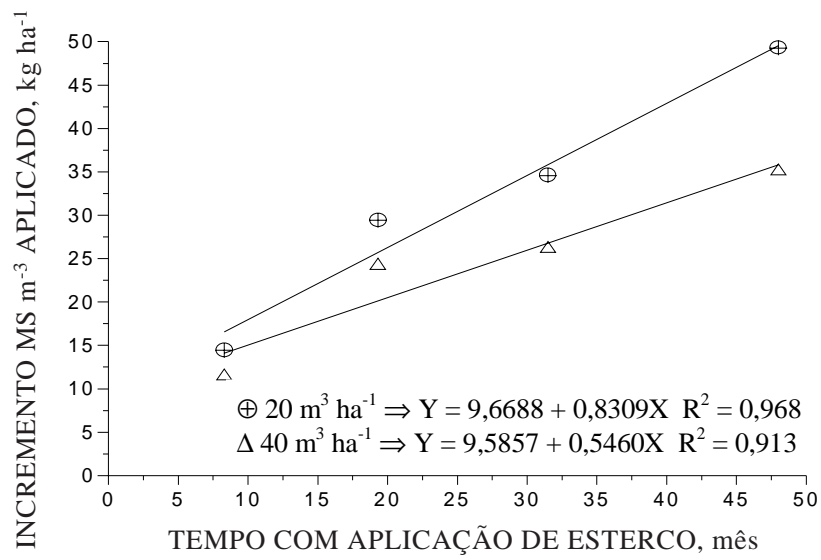

Figura 2. Incremento acumulado na produção de matéria seca em pastagem natural por $\mathrm{m}^{3}$ de esterco líquido de suínos aplicado.

de nitrogênio estão muito próximos dos valores encontrados por Sullivan et al. (2000), quando aplicaram diferentes doses de nitrogênio na forma de esterco bovino em pastagem perene.

Pode-se inferir que em torno de $70 \%$ do $\mathrm{N}$ aplicado na forma de esterco líquido de suínos pode tornar-se um poluente, uma vez que apresenta alta mobilidade no solo. I sso é justificado pelo fato de terem sido adicionados ao solo, durante os quatro anos, 1.848 e $3.696 \mathrm{~kg} \mathrm{ha}^{-1}$ de N, via esterco, nas doses de 20 e $40 \mathrm{~m}^{3} \mathrm{ha}^{-1}$, respectivamente, o que representou apenas 17,0 e 1,0\% de incremento no $\mathrm{N}$ total no solo na camada de $0-20 \mathrm{~cm}$ (Durigon, 2000).

A superposição das figuras 1 e 3 mostra similaridade na distribuição das linhas de resposta, evidenciando que a absorção de $\mathrm{N}$ pelas plantas foi determinada principal mente pela interação entre o potencial genético de produção de matéria seca e os demais fatores que determinaram a produção.

A quantidade de fósforo acumulada na matéria seca da pastagem após 48 meses de aplicação de esterco líquido de suínos foi de 216 e $292 \mathrm{~kg} \mathrm{ha-1,}$ nas doses de 20 e $40 \mathrm{~m}^{3}$ ha-1, respectivamente, o que representa um aproveitamento deapenas 8,1 e5,8\% do total de fósforo aplicado na forma de esterco nas respectivas doses (Figura 4).

Esses baixos percentuais de aproveitamento pelas plantas do $\mathrm{P}$ aplicado indicam que o esterco líquido de suínos adiciona ao sistema quantidades de $P$ muito acima das necessidades das plantas. A conseqüência é a acumulação de $\mathrm{P}$ no solo, dada a sua característica de apresentar alta energia de ligação com a fração mineral do solo.

Deve-se considerar o potencial de resposta ao $\mathrm{P}$ aplicado via esterco, porque o teor no sol o era médio, segundo CFSRS/SC (1995), e ainda pode-se questionar sua disponibilidade às plantas na

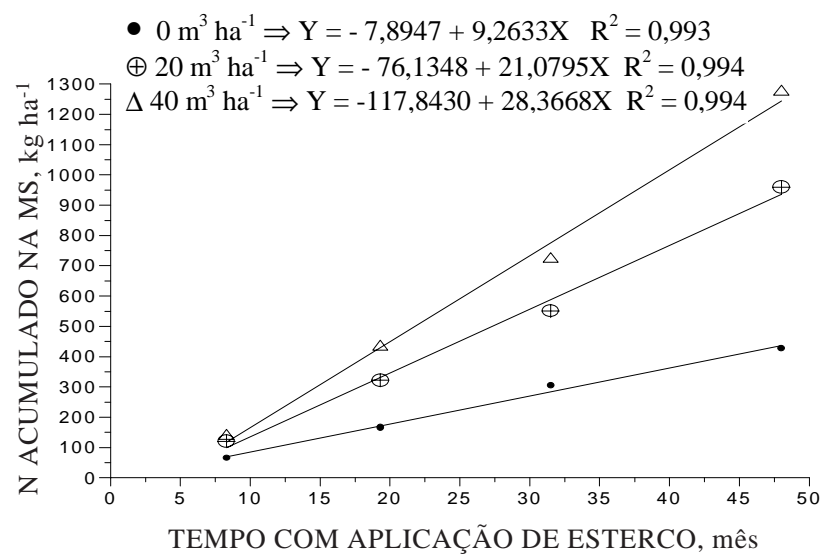

Figura 3. Nitrogênio acumulado na matéria seca em pastagem natural com aplicação de doses de esterco líquido de suínos.

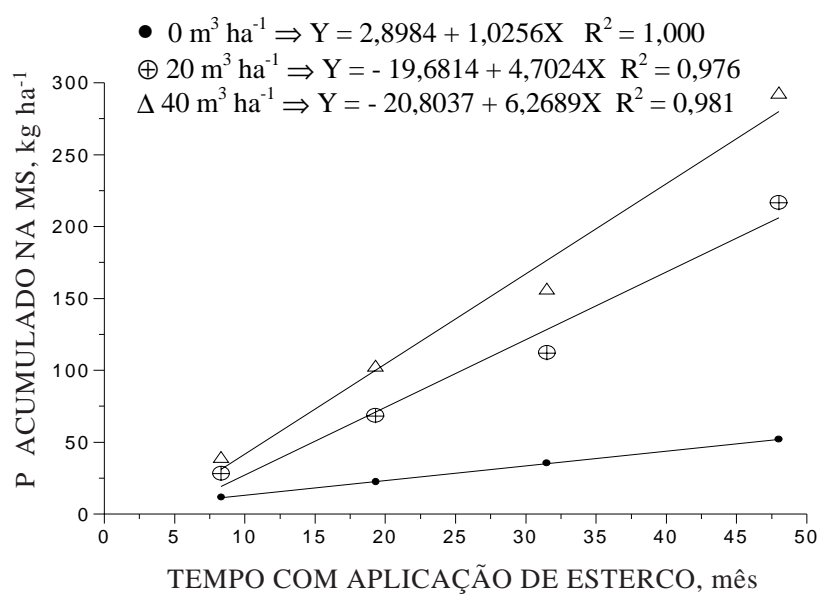

Figura 4. Fósforo acumulado na matéria seca em pastagem natural com aplicação de doses de esterco líquido de suínos.

presença de al tos teores deAl trocável no solo, antes do início das aplicações de esterco. Entretanto, é necessário ressaltar que grande parte do $\mathrm{P}$ aplicado via esterco também está em formas pouco solúveis, principal mente como fosfato de cál cio e P-orgânico. Por essa razão, nesse mesmo trabal ho, o incremento no teor de $\mathrm{P}$ no solo, na camada de $0-2,5 \mathrm{~cm}$, foi de 3.943 e $6.710 \%$ com as doses de 20 e $40 \mathrm{~m}^{3} \mathrm{ha}^{-1}$, respectivamente, embora Durigon (2000) tenha utilizado o método Mehlich, que sol ubiliza o fosfato de cálcio, o que superestima os teores de $\mathrm{P}$ no solo onde foi aplicado esterco.

A composição botânica da pastagem natural foi influenciada, durante os quatro anos deste mesmo trabalho (Durigon, 2000), tendo-se verificado que onde não foi utilizado esterco havia grande diversidade de espécies, com predomínio de grama forquilha (Paspalum notatum) e desmodium 
(Desmodium sp.), enquanto com esterco havia poucas espécies, com predomínio de gramíneas como o capim-azedo (Paspalum conjugatum) e cyperáceas, as quais apresentam menor demanda de fósforo em relaçãoàs leguminosas. Por sua vez, Gatiboni (1999), quando avaliou o mel horamento de pastagem com a introdução de espécies forrageiras no inverno em solo de textura superficial arenosa e sob efeito de diferentes fosfatos, solúveis e naturais, associados ou não à calagem, observou que, mesmo sem adição de fósforo, houve diminuição da participação de Eryngium ciliatum (caraguatá) na composição da pastagem.

Com relação ao potássio, a quanti dadeacumulada na matéria seca após 48 meses de aplicação de esterco foi de 1.073 e $1.356 \mathrm{~kg} \mathrm{ha}^{-1}$, nas doses de 20 e $40 \mathrm{~m}^{3} \mathrm{ha}^{-1}$, respectivamente, representando um aproveitamento de 45 e $32 \%$ do total de potássio contido no esterco (Figura 5).

Considerando que praticamente todo o $\mathrm{K}$ adicionado via esterco está na forma disponível às plantas e serem os teores deK trocável inicialmente no solo muito altos, uma vez que acima de $120 \mathrm{mg} \mathrm{dm}^{-3}$ é considerado al to (CFSRS/SC, 1995) e havia em média $191 \mathrm{mg} \mathrm{dm}^{-3}$ (Quadro 1), estes percentuais de $\mathrm{K}$ absorvidos são muito expressivos e indicam que as quantidades de $\mathrm{K}$ exportado pela forragem são muito altas.

Durigon (2000) mostrou, nestemesmo experimento, que, diferentemente dos demais nutrientes, os teores de K nosolo diminuíram em média 51 e $38 \%$, quando foram aplicadas as doses de 20 e $40 \mathrm{~m}^{3} \mathrm{ha}^{-1}$, respectivamente. Como conseqüência, os teores de K disponível no solo ficaram abaixo do nível crítico, que é de $80 \mathrm{mg} \mathrm{dm}^{-3}$, mesmo com as 28 aplicações das doses de 20 e $40 \mathrm{~m}^{3} \mathrm{ha}^{-1}$, durante os quatro anos.

Todavia, Senger et al. (1996), anal isando os teores minerais em pastagens do Rio Grande do Sul, verificaram que em apenas $16,4 \%$ das amostras de tecido vegetal analisadas o teor deK era insuficiente para atender ao requerimento mínimo para bovinos.

O cálcio acumulado na matéria seca, após 48 meses de aplicação de esterco líquido de suínos, foi de 424 e $509 \mathrm{~kg} \mathrm{ha}^{-1}$ nas doses de 20 e $40 \mathrm{~m}^{3} \mathrm{ha}^{-1}$, respectivamente, representando um aproveitamento de 43 e $29 \%$ do total de cálcio contido no esterco aplicado (Figura 6). Por outro lado, os incrementos de cálcio no solo foram observados até à profundidade de $5,0 \mathrm{~cm}$ em percentual médio de $43 \%$, com pouca influência da dose, com pequena diferença no residual das doses de 20 e $40 \mathrm{~m}^{3} \mathrm{ha}^{-1}$ (Durigon, 2000).

O magnésio acumulado na matéria seca após 48 meses de aplicação do esterco foi de 495 e $661 \mathrm{~kg} \mathrm{ha}^{-1}$, nas doses de 20 e $40 \mathrm{~m}^{3} \mathrm{ha}^{-1}$, respectivamente, representando um aproveitamento de 70 e $50 \%$ do total do magnési o contido no esterco aplicado (Figura 7). Mesmo com estes altos percentuais de absorção, os acréscimos nos teores de magnésio no sol o chegaram a atingir, em média, $265 \%$ na camada de 5,0 a 20,0 cm, demonstrando tanto a maior mobilidade do magnésio no solo, quanto sua maior extração pelo método $\mathrm{KCl}\left(1\right.$ mol L $\left.{ }^{-1}\right)$ em relação ao cálcio.

A resposta da pastagem natural às quantidades de $\mathrm{N}, \mathrm{P}, \mathrm{K}, \mathrm{Ca}$ e $\mathrm{Mg}$ contidas no esterco aplicado demonstra que na definição da quantidade deesterco a ser aplicada não basta apenas considerar a produção de matéria seca, mas também os parâmetros que indiquem a eficiência de aproveitamento do esterco pelas plantas.

\section{Aplicação de esterco líquido de suínos nas differentes estações do ano}

Os aumentos na produção de matéria seca na pastagem natural pel o uso de esterco ocorreram em

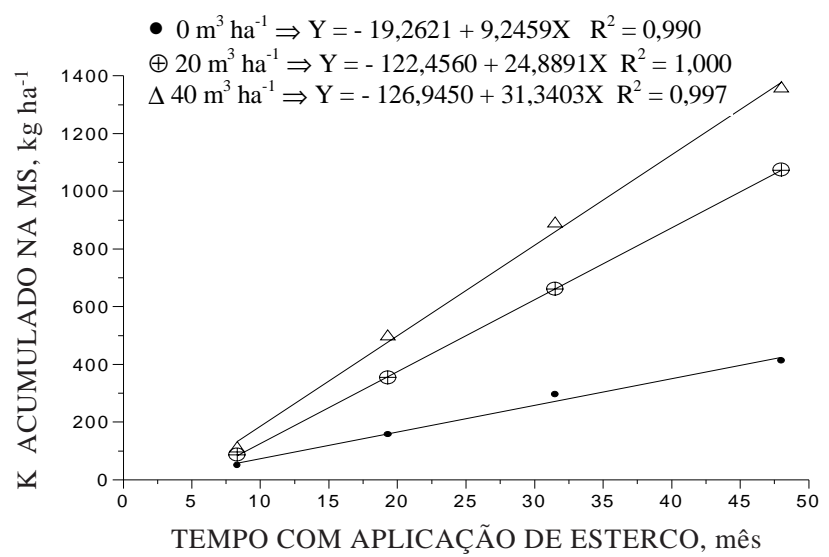

Figura 5. Potássio acumulado na matéria seca em pastagem natural com aplicação de doses de esterco líquido de suínos.

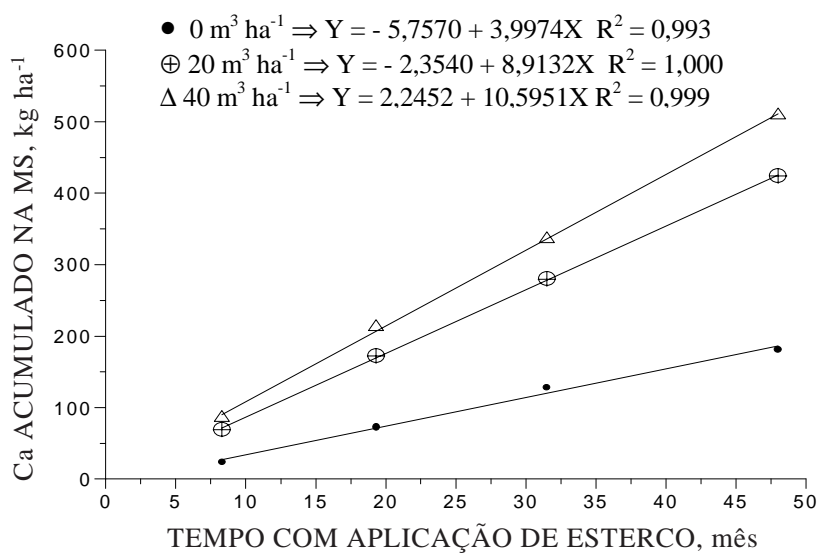

Figura 6. Cálcio acumulado na matéria seca em pastagem natural com aplicação de doses de esterco líquido de suínos. 


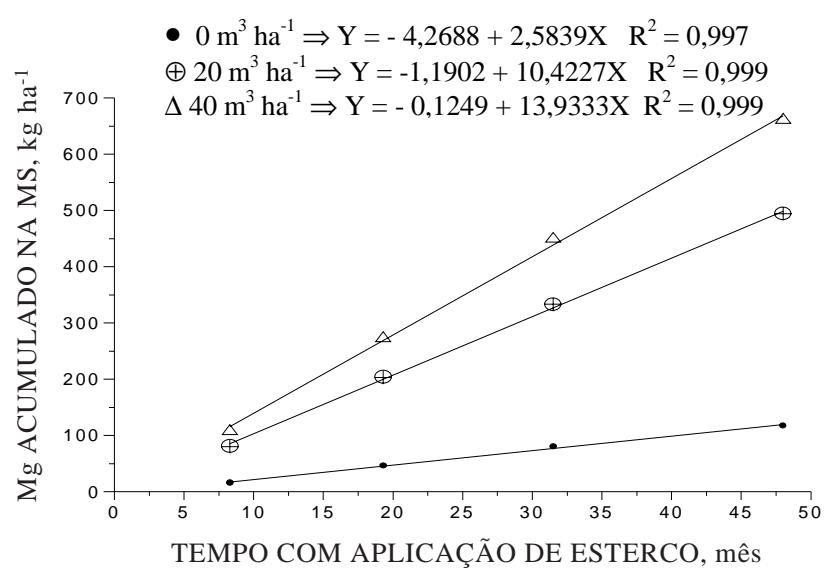

Figura 7. Magnésio acumulado na matéria seca em pastagem natural com aplicação de doses de esterco líquido de suínos.

todas as estações doano, mas foram mais expressivos no verão e na primavera (Quadro 3).

A produção de matéria seca da pastagem natural sem a aplicação de esterco foi 117, 200 e $95 \%$ superior nas estações de primavera, verão e outono, respectivamente, em relação à estação de inverno. Com o uso de $20 \mathrm{~m}^{3}$ ha-1 $^{-1}$ de esterco, a produção de matéria seca pela pastagem natural foi 89,76 e $05 \%$ superior nas estações de primavera, verão e outono, respectivamente, enquanto, com a aplicação de $40 \mathrm{~m}^{3} \mathrm{ha}^{-1}$ do esterco, o acréscimo foi de 100, 85 e $14 \%$ nas estações de primavera, verão e outono, respectivamente, em relação à estação de inverno. E mbora tenha sido observada tendência de aumento na produção de matéria seca com o uso de $40 \mathrm{~m}^{3} \mathrm{ha}^{-1}$, não houve diferença estatística em relação à dose de $20 \mathrm{~m}^{3} \mathrm{ha}^{-1}$, mas apenas em comparação com a área onde não foi aplicado esterco.

As menores produções de matéria seca no outono e inverno demandaram menos nutrientes, resultando em menor quantidadeabsorvida de N, P, $\mathrm{K}$, Ca e Mg pelas plantas nessas estações do ano (Quadro 4).
Nas estações de outono e inverno, quando não foi aplicado esterco, o teor de fósforo presente na matéria seca na pastagem natural estava abaixo do requerimento mínimo para bovinos de corte que é de $0,18 \%$ (National Research Council, 1984). Por outro lado, a aplicação do esterco proporcionou concentrações de fósforo na pastagem natural superiores ao requerimento mínimo exigi do em todas as estações do ano. I sso evidencia que o fósforo aplicado via esterco deve ser um dos principais responsáveis pel o acréscimo na produção de matéria seca na pastagem, visto que a maioria dos solos brasileiros apresenta disponibilidade de fósforo naturalmente baixa, potencializada pela acidez.

Após analisar os teores minerais em pastagens doRio Grande doSul, Senger et al. (1996) verificaram que $98,2 \%$ das amostras deteci do vegetal analisadas não atingiram o percentual de 0,18 \% deP. Por isso, além dos benefícios às plantas do fósforo aplicado via esterco, também pode haver diminuição na toxidez por alumínio, causada pela complexação com fósforo ou com compostos orgânicos mais reativos resultantes do esterco aplicado.

A eficiência nutricional em pastagem natural com aplicação de esterco líquido de suínos foi maior nas estações de verão e primavera em relação ao outono e inverno para os nutrientes $\mathrm{N}, \mathrm{P}, \mathrm{K}, \mathrm{Ca}$ e $\mathrm{Mg}$ (Quadro 5). Apenas para o K não houve diferenças significativas entre as estações do ano, apesar de apresentar comportamento similar ao dos demais nutrientes.

Em todas as estações do ano, houve decréscimo na eficiência nutricional com a utilização de $40 \mathrm{~m}^{3} \mathrm{ha}^{-1}$ em relação à dose de $20 \mathrm{~m}^{3} \mathrm{ha}^{-1}$, embora essas diferenças somentetenham sido significativas para o P no verão. I sso pode ser explicado pelo alto coeficiente de variação encontrado, pois, além da variação na produção de matéria seca em cada estação do ano, houve variação entre os anos de condução do experimento. Comparando com a dose de $20 \mathrm{~m}^{3}$ ha-1, observa-se que, na média das estações do ano, o decréscimo na eficiência nutricional com a utilização de $40 \mathrm{~m}^{3}$ ha-1 foi de 31, 26, 27, 26 e $29 \%$, para N, $\mathrm{P}, \mathrm{K}, \mathrm{Ca}$ e Mg, respectivamente.

Quadro 3. Produção de matéria seca em pastagem natural com aplicação de doses de esterco líquido de suínos de acordo com as estações do ano

\begin{tabular}{|c|c|c|c|c|}
\hline \multirow{2}{*}{ Dose de esterco } & \multicolumn{4}{|c|}{ E stação } \\
\hline & Verão & Outono & Inverno & Primavera \\
\hline $\mathrm{m}^{3} \mathrm{ha}^{-1}$ & \multicolumn{4}{|c|}{$-\mathrm{kg} \mathrm{ha}^{-1} \mathrm{dia}^{-1}$} \\
\hline 0 & $25,51 \mathrm{Ab}$ & $16,52 \mathrm{Bb}$ & $8,48 \mathrm{Cb}$ & $18,43 \mathrm{ABb}$ \\
\hline 20 & $44,86 \mathrm{Aab}$ & $26,75 \mathrm{Bab}$ & $25,55 \mathrm{Ba}$ & $48,31 \mathrm{Aa}$ \\
\hline 40 & $55,09 \mathrm{Aa}$ & $33,90 \mathrm{Ba}$ & $29,79 \mathrm{Ba}$ & $59,49 \mathrm{Aa}$ \\
\hline
\end{tabular}

Médias seguidas de mesma letra maiúscula, na linha, e minúscula, na coluna, não diferem pelo teste Duncan a 5 \%. Coeficientes de variação médios de $39 \%$, para as estações do ano, e de $40 \%$, para as doses de esterco. 
Quadro 4. Quantidade de nutrientes acumulados na matéria seca em pastagem natural com aplicação de doses de esterco líquido de suínos de acordo com as estações do ano

\begin{tabular}{|c|c|c|c|c|c|}
\hline \multirow{2}{*}{ Nutriente } & \multirow{2}{*}{ Dose de esterco } & \multicolumn{4}{|c|}{ E stação } \\
\hline & & Verão & Outono & Inverno & Primavera \\
\hline & $\mathrm{m}^{3} \mathrm{ha}^{-1}$ & \multicolumn{4}{|c|}{$-\mathrm{kg} \mathrm{ha}^{-1} \mathrm{dia}^{-1}$} \\
\hline $\mathrm{N}$ & $\begin{array}{r}0 \\
20 \\
40\end{array}$ & $\begin{array}{l}0,39 \mathrm{Ab} \\
0,70 \mathrm{Aa} \\
0,88 \mathrm{ABa}\end{array}$ & $\begin{array}{l}0,26 \mathrm{ABC} \\
0,54 \mathrm{Ab} \\
0,75 \mathrm{Ba}\end{array}$ & $\begin{array}{l}0,17 \mathrm{Bb} \\
0,61 \mathrm{Aa} \\
0,80 \mathrm{Ba}\end{array}$ & $\begin{array}{l}0,36 \mathrm{Ab} \\
0,87 \mathrm{Aa} \\
1,17 \mathrm{Aa}\end{array}$ \\
\hline $\mathrm{P}$ & $\begin{array}{r}0 \\
20 \\
40\end{array}$ & $\begin{array}{l}0,06 \mathrm{Ab} \\
0,19 \mathrm{Aa} \\
0,27 \mathrm{Aa}\end{array}$ & $\begin{array}{l}0,03 \mathrm{ABC} \\
0,12 \mathrm{Ab} \\
0,18 \mathrm{ABa}\end{array}$ & $\begin{array}{l}0,02 \mathrm{Bb} \\
0,11 \mathrm{Aa} \\
0,15 \mathrm{Ba}\end{array}$ & $\begin{array}{l}0,04 \mathrm{ABb} \\
0,18 \mathrm{Aa} \\
0,23 \mathrm{ABa}\end{array}$ \\
\hline $\mathrm{K}$ & $\begin{array}{r}0 \\
20 \\
40\end{array}$ & $\begin{array}{l}0,42 \mathrm{Ab} \\
0,89 \mathrm{Aa} \\
0,90 \mathrm{Ba}\end{array}$ & $\begin{array}{l}0,25 \mathrm{BCb} \\
0,55 \mathrm{Ba} \\
0,77 \mathrm{Ba}\end{array}$ & $\begin{array}{l}0,13 \mathrm{Cb} \\
0,54 \mathrm{Ba} \\
0,65 \mathrm{Ba}\end{array}$ & $\begin{array}{l}0,32 \mathrm{ABc} \\
0,97 \mathrm{Ab} \\
1,43 \mathrm{Aa}\end{array}$ \\
\hline $\mathrm{Ca}$ & $\begin{array}{r}0 \\
20 \\
40\end{array}$ & $\begin{array}{l}0,21 \mathrm{Ab} \\
0,32 \mathrm{ABab} \\
0,42 \mathrm{Aa}\end{array}$ & $\begin{array}{l}0,11 \mathrm{Bb} \\
0,22 \mathrm{Ba} \\
0,29 \mathrm{Ba}\end{array}$ & $\begin{array}{l}0,10 \mathrm{Bb} \\
0,31 \mathrm{ABa} \\
0,30 \mathrm{Ba}\end{array}$ & $\begin{array}{l}0,13 \mathrm{Bc} \\
0,35 \mathrm{Ab} \\
0,42 \mathrm{Aa}\end{array}$ \\
\hline $\mathrm{Mg}$ & $\begin{array}{r}0 \\
20 \\
40\end{array}$ & $\begin{array}{l}0,15 \mathrm{Ab} \\
0,42 \mathrm{Aa} \\
0,57 \mathrm{Aa}\end{array}$ & $\begin{array}{l}0,08 \mathrm{Bc} \\
0,24 \mathrm{Bb} \\
0,32 \mathrm{Ba}\end{array}$ & $\begin{array}{l}0,06 \mathrm{Bc} \\
0,30 \mathrm{Bb} \\
0,37 \mathrm{Ba}\end{array}$ & $\begin{array}{l}0,08 \mathrm{Bc} \\
0,43 \mathrm{Ab} \\
0,58 \mathrm{Aa}\end{array}$ \\
\hline
\end{tabular}

Médias seguidas de mesma letra maiúscula, na linha, e minúscula, na coluna, não diferem pelo teste Duncan a $5 \%$. Coeficiente de variação médio: 40,3, 56,3, 38,7, 28,6 e 27,7 \% para N, P, K, Ca e Mg, respectivamente, nas doses de esterco e 37,1, 54,8, 41,5, 28,4 e $26,0 \%$, para N, P, K, Ca e Mg, respectivamente, nas estações do ano.

Quadro 5. Eficiência nutricional(1) em pastagem natural com aplicação de doses de esterco líquido de suínos de acordo com as estações do ano

\begin{tabular}{cccccc}
\hline \multirow{2}{*}{ Nutriente } & Dose de esterco & \multicolumn{3}{c}{ Estação } \\
\cline { 4 - 6 } & & Verão & Outono & Inverno & Primavera \\
\hline & $\mathrm{m}^{3} \mathrm{ha}^{-1}$ & & & & \\
$\mathrm{~N}$ & 20 & $21,35 \mathrm{ABa}$ & $8,28 \mathrm{Ba}$ & $18,27 \mathrm{ABa}$ & $29,12 \mathrm{Aa}$ \\
& 40 & $15,39 \mathrm{Aba}$ & $6,60 \mathrm{Ba}$ & $11,84 \mathrm{ABa}$ & $20,85 \mathrm{Aa}$ \\
$\mathrm{P}$ & 20 & $23,74 \mathrm{ABa}$ & $11,48 \mathrm{Ba}$ & $11,88 \mathrm{Ba}$ & $35,34 \mathrm{Aa}$ \\
& 40 & $16,72 \mathrm{ABb}$ & $9,63 \mathrm{Ba}$ & $8,00 \mathrm{Ba}$ & $26,87 \mathrm{Aa}$ \\
$\mathrm{K}$ & 20 & $32,42 \mathrm{Aa}$ & $17,36 \mathrm{Aa}$ & $26,01 \mathrm{Aa}$ & $44,56 \mathrm{Aa}$ \\
& 40 & $26,38 \mathrm{Aa}$ & $15,33 \mathrm{Aa}$ & $18,02 \mathrm{Aa}$ & $28,53 \mathrm{Aa}$ \\
$\mathrm{Ca}$ & 20 & $73,24 \mathrm{ABa}$ & $28,86 \mathrm{Ba}$ & $59,61 \mathrm{Ba}$ & $114,01 \mathrm{Aa}$ \\
& 40 & $52,75 \mathrm{ABa}$ & $23,45 \mathrm{Ba}$ & $37,09 \mathrm{Ba}$ & $90,60 \mathrm{Aa}$ \\
& 20 & $63,48 \mathrm{ABa}$ & $26,03 \mathrm{Ba}$ & $53,66 \mathrm{Ba}$ & $125,42 \mathrm{Aa}$
\end{tabular}

Médias seguidas de mesma letra maiúscula, na linha, e minúscula, na coluna, não diferem pelo teste Duncan a 5 \%. Coeficiente de variação médio: $62,5,81,1,67,3,85,3$ e 74,1 \% para N, P, K, Ca e Mg, respectivamente, nas doses de esterco e 62,1, 66,9, 61,3, 76,5 e $65,4 \%$ para N, P, K, Ca e Mg, respectivamente, nas estações do ano. ${ }^{(1)}$ Eficiência nutricional =kg de MS produzida com esterco - kg de MS produzido sem esterco/kg de nutriente aplicado através do esterco.

A eficiência de aquisição de nutrientes na pastagem natural foi maior nas estações de verão e primavera para a maioria dos nutrientes analisados (Quadro 6). Quanto às doses aplicadas, houve decréscimo na eficiência de aquisição de nutrientes com a utilização de $40 \mathrm{~m}^{3} \mathrm{ha}^{-1} \mathrm{em}$ todas as estações do ano; todavia, essas diferenças não foram significativas em alguns casos em razão do alto coeficiente de variação encontrado.

A eficiência nutricional ea eficiência de aquisição de nutrientes em pastagem natural com aplicação deestercolíquido de suínos podem ser incrementadas 


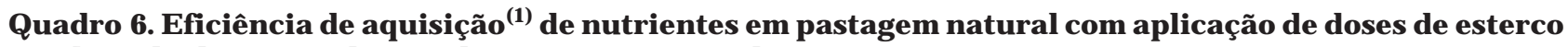
líquido de suínos de acordo com as estações do ano

\begin{tabular}{|c|c|c|c|c|c|}
\hline \multirow{2}{*}{ Nutriente } & \multirow{2}{*}{ Dose de esterco } & \multicolumn{4}{|c|}{ E stação } \\
\hline & & Verão & Outono & Inverno & Primavera \\
\hline & $\mathrm{m}^{3} \mathrm{ha}^{-1}$ & & & & \\
\hline $\mathrm{N}$ & $\begin{array}{l}20 \\
40\end{array}$ & $\begin{array}{l}0,29 \mathrm{ABa} \\
0,25 \mathrm{Bb}\end{array}$ & $\begin{array}{l}0,18 \mathrm{Ba} \\
0,16 \mathrm{Ba}\end{array}$ & $\begin{array}{l}0,27 \mathrm{ABa} \\
0,19 \mathrm{Ba}\end{array}$ & $\begin{array}{l}0,41 \mathrm{Aa} \\
0,40 \mathrm{Aa}\end{array}$ \\
\hline$P$ & $\begin{array}{l}20 \\
40\end{array}$ & $\begin{array}{l}0,14 \mathrm{Aa} \\
0,11 \mathrm{Aa}\end{array}$ & $\begin{array}{l}0,09 \mathrm{Aa} \\
0,07 \mathrm{Aa}\end{array}$ & $\begin{array}{l}0,06 \mathrm{Aa} \\
0,05 \mathrm{Aa}\end{array}$ & $\begin{array}{l}0,16 \mathrm{Aa} \\
0,12 \mathrm{Aa}\end{array}$ \\
\hline K & $\begin{array}{l}20 \\
40\end{array}$ & $\begin{array}{l}0,52 \mathrm{Aa} \\
0,39 \mathrm{Ab}\end{array}$ & $\begin{array}{l}0,50 \mathrm{Ba} \\
0,46 \mathrm{Aa}\end{array}$ & $\begin{array}{l}0,61 \mathrm{ABa} \\
0,43 \mathrm{Aa}\end{array}$ & $\begin{array}{l}0,61 \mathrm{Aa} \\
0,48 \mathrm{Aa}\end{array}$ \\
\hline $\mathrm{Ca}$ & $\begin{array}{l}20 \\
40\end{array}$ & $\begin{array}{l}0,47 \mathrm{ABa} \\
0,38 \mathrm{Ab}\end{array}$ & $\begin{array}{l}0,25 \mathrm{Ba} \\
0,27 \mathrm{Aa}\end{array}$ & $\begin{array}{l}0,51 \mathrm{ABa} \\
0,24 \mathrm{Ab}\end{array}$ & $\begin{array}{l}0,66 \mathrm{Aa} \\
0,46 \mathrm{Ab}\end{array}$ \\
\hline $\mathrm{Mg}$ & $\begin{array}{l}20 \\
40\end{array}$ & $\begin{array}{l}0,76 \mathrm{Aa} \\
0,54 \mathrm{Ab}\end{array}$ & $\begin{array}{l}0,29 \mathrm{Ba} \\
0,24 \mathrm{Ba}\end{array}$ & $\begin{array}{l}0,66 \mathrm{Ba} \\
0,45 \mathrm{Bb}\end{array}$ & $\begin{array}{l}0,81 \mathrm{Aa} \\
0,67 \mathrm{Ab}\end{array}$ \\
\hline
\end{tabular}

Médias seguidas de mesma letra maiúscula na linha e minúscula na coluna, não diferem pelo teste Duncan a $5 \%$. Coeficiente de variação médio: 42,8, 73,1, 34,7, 30,8 e 22,1 \% para N, P, K, Ca e Mg, respectivamente, nas doses de esterco e 40,4, 70,4, 32,3, 29,0 e $23,4 \%$ para $\mathrm{N}, \mathrm{P}, \mathrm{K}, \mathrm{Ca}$ e $\mathrm{Mg}$, respectivamente, nas estações do ano. ${ }^{(1)}$ Eficiência de aquisição de nutrientes = kg de nutriente absorvido com aplicação de esterco - kg de nutriente absorvido sem aplicação de esterco/kg de nutriente aplicado através do esterco.

com a introdução de espécies forrageiras que apresentem maior capacidade de produção de matéria seca e, conseqüentemente, maior demanda por nutrientes.

\section{CONCLUSÕES}

1. A aplicação de $20 \mathrm{~m}^{3}$ ha-1 de estercolíquido de suínos em interval os de 45 a 60 dias foi mais eficiente para o suprimento de nutrientes às plantas da pastagem natural.

2. A quantidade de fósforo absorvida pelas plantas na pastagem natural foi muito baixa em relação à quantidade aplicada via esterco.

3. Deve-se dar especial atenção às concentrações de potássio e magnésio presentes no esterco líquido desuínos, consi derando as al tas taxas de exportação destes nutrientes via matéria seca da pastagem.

4. Devem-se reduzir as quantidades de esterco aplicadas nas estações de outono e inverno, por causa das restrições cl imáticas à produção de matéria seca na pastagem natural.

\section{AGRADE CIMENTOS}

Os autores agradecem aos produtores pertencentes ao Condomínio de Suinocultores e a colaboração do Engo-Agro. Cezar Augusto Medeiros e do Técnico Agrícola J osé Valdetar da Silva Gomes, ambos da
EMATER/RS; aos Engos.-Agros. Aldo RobertoTisott e J eferson Diekow, bolsistas de iniciação científica do programa PIBIC-CNPq e FAPERGS, respectivamente, além dos atuais bolsistas de iniciação científica Frederico Costa Beber Vieira (PIBICCNPq), Miguel Gustavo Herbes (BIC-FAPERGS) e Naracelis Poletto (BIC-FIPE/UFSM).

\section{LITERATURA CITADA}

AITA, C. Aproveitamento dos dejetos desuínos como fertilizante. Chapecó, Empresa de Pesquisa Agropecuária de Santa Catarina, 1987. 14p.

BARCELLOS, L.A.R. Avaliação do potencial fertilizante do esterco líquido de bovinos. Santa Maria, Universidade Federal de Santa Maria, 1992. 108p. (Tese de Mestrado)

BRASIL. Ministério da Agricultura. Levantamento de reconhecimento dos solos do estado do Rio Grande do Sul. Convênio MA/DPP-SA/DRNR. Recife, 1973. 431p. (Boletim Técnico, 30)

CHAMBERS, B.J .; SMITH, K.A. \& PAIN, B.F. Strategies to encourage better use of nitrogen in animal manures. Soil Use Manag., 16:157-161, 2000.

COMISSÃO DE FERTILIDADE DO SOLO - CFSRS/SC. Recomendações de adubação e calagem para o estado do Rio Grande do Sul e Santa Catarina. 3.ed. Passo Fundo, Sociedade Brasileira de Ciência doSolo, Empresa Brasileira de Pesquisa Agropecuária, 1995. 224p.

DURIGON, R. Esterco líquido de suínos em pastagem natural e características químicas do solo. Santa Maria, Universidade Federal de Santa Maria, 2000. 46p. (Tese de Mestrado) 
EMPRESA BRASILEIRA DE PESQUISA AGROPECUÁRIA EMBRAPA. Sistema brasileiro de dassificação de solos. Brasília, 1999. 412p

GATIBONI, L.C. Oferta de forragem de pastagem natural afetada pela adubação fosfatada e introdução de espécies forragei ras de inverno. Santa Maria, UniversidadeFederal de Santa Maria, 1999. 63p. (Tese de Mestrado)

INSTITUTO BRASILEIRO DE GEOGRAFIA E ESTATÍSTICAIBGE. In: ANUÁRIO ESTATÍSTICO DO RIO GRANDE DO SUL. Porto Alegre, Secretaria da Coordenação e Planejamento, 1995. p. 316-326.

J ACQUES, A.V.; SAIBRO, J.C. \& LOBATO, J.F. Sistema de produção de forragem para a Depressão Central, RS. In: FEDERACITE - CADEIAS FORRAGEIRAS REGIONAIS. Porto Alegre, 1995. p.13-28.

KONZEN, E.A.; SANTOS, H.L. \& PEREIRA FILHO, I.A.P. Utilização do esterco líquido na adubação de milho. Sete Lagoas, Empresa Brasileira de Pesquisa Agropecuária, 1989. $17 p$.

NATIONAL RESEARCH COUNCIL-NRC. Nutrient requirements of beef cattle. 6.ed. Washington, D.C., National Academy of Sciences/National Research Council, 1984. 242p.
SCHERER, E.E.; CASTILHOS, E.G. \& AITA. C. Utilização de esterco líquido de suínos como fonte de nitrogênio para as culturas de milho e feijão. Chapecó, Empresa de Pesquisa Agropecuária de Santa Catarina, 1986. 4p. (Apostila)

SCHMITT, D.R. Avaliação técnica e econômica da distribuição de esterco líquido de suínos. Santa Maria, Universidade Federal de Santa Maria, 1995. 151p (Tese de Mestrado)

SENGER, C.C.D.; SANCHEZ, L.M.B.; PIRES, M.B.G. \& KAMINSKI, J. Teores minerais em pastagens do Rio Grande do Sul. Pesq. Agropec. Bras., 31:897-904, 1996.

SULLIVAN, D.M.; COGGER, C.G.; BARY, A.I \& \& FRANSEN, S.C. Timing of dairy manure applications to perennial grass on well drained and poorly drained soils. J. Soil Water Conserv., 55:147-152, 2000.

TEDESCO, M.J .; GIANELLO, C.; BISSANI, C.A.; BOHNEN, H. \& VOLKWEISS, S.J. Análises de solo, plantas e outros materiais. 2.ed. Porto Alegre, Universidade Federal do Rio Grande do Sul, 1995. 174 p. (Boletim Técnico, 5)

VETTER, H. \& KOWALEWSKY, H.H. Gülle Ausbringen Unweltfreundlich, Pflanzen - und Bodengerecht. Frankfurt, 1986. 61p. 